\title{
Significance and influence of the ambient temperature as a rate factor of steel reinforcement corrosion
}

\author{
V ŽIVICA \\ Institute of Construction and Architecture of the Slovak Academy of Sciences, Bratislava, Slovak Republic
}

MS received 10 July 2002

\begin{abstract}
The rate of corrosion of reinforcement being an electrochemical process, undoubtedly is dependent even on the level of the ambient temperature. Therefore, the ambient temperature seems to be an important factor of the corrosion rate and the durability of the reinforced concrete structures in aggressive environment.

The present data on the influence and significance of the ambient temperature in the process of corrosion of reinforcement of the reinforced structures are surprisingly limited and poor. It seems that it is supposed to be a simple increase of corrosion rate when the ambient temperature is increased.

The lack of information was a motivation for the present study. It was aimed at the experimental research of the influence of the increase of the ambient temperature on the rate of chloride induced corrosion of steel reinforcement. The results obtained show that the influence of the studied factor is more complex showing an acceleration effect till a temperature of $40^{\circ} \mathrm{C}$ diversified by the inhibition effects with further increase of the ambient temperature.
\end{abstract}

Keywords. Chloride induced corrosion; concrete reinforcement; ambient temperature; corrosion rate; oxygen; water.

\section{Introduction}

As it is well known, the ambient temperature is a very vital factor for the possibility of every chemical reaction and its rate. Undoubtedly, it is the same for the corrosion of steel reinforcement being an electrochemical reaction.

The dependence of the rate of a chemical reaction on the temperature of the reaction system in the Arrhenius equation is:

$$
k=A \cdot e(-E / R T),
$$

where $k$ is the rate constant, $A$ the frequency factor, $E$ the activation energy, $T$ the temperature and $R$ the gaseous constant. It is evident that the rate of reaction increased when the temperature increased. According to this even the increase of the rate of corrosion of steel reinforcement may be expected when the ambient temperature is increased.

It is known that electrochemical process of corrosion of steel reinforcement consists of two mutually conditioning coupled anodic and cathodic reactions:

$$
\begin{aligned}
& \text { Anodic reaction, } \mathrm{Fe} \rightarrow \mathrm{Fe}^{2+}+2 e^{1-}, \\
& \text { Cathodic reaction, } 2 e^{1-}+\mathrm{H}_{2} \mathrm{O}+\frac{1}{2} \mathrm{O}_{2} \rightarrow 2 \mathrm{OH}^{1-} .
\end{aligned}
$$

It is evident that reaction or corroding system, respectively from the view point of composition is heterogeneous consisting of solid (iron), liquid (water), and gaseous (oxygen) reactants. This fact is a significant factor from view point of the temperature dependence of the rate. It is known that a further significant factor of a chemical reaction is the concentration of the reactants. Their decrease results in slowing down or inhibition of the reaction. Two reactants of the steel corrosion, water and oxygen, are sensitive to the temperature changes. As the temperature increased the solubility of oxygen in water significantly decreased, and water vapour tension significantly increased. Both effects resulted in a significant concentration decrease of water and oxygen as reactants for the process of steel corrosion and in the lowering down of the reaction rate.

Then both effects are able to inhibit the steel corrosion regardless of the acceleration effects of the temperature increase expressed by the Arrhenius law.

The influence of the increase of temperature on the oxygen solubility in water and the tension of water vapour is shown in figure 1 . It may be seen that increase of the temperature from 20 to $50^{\circ} \mathrm{C}$ represents the decrease of the oxygen solubility of about $60 \%$, and the increase of the vapour tension of about $330 \%$. It documents a possibility of a drastic change in stoichiometric conditions in the process of steel corrosion when the ambient temperature is increased as a consequence of the decrease of the concentration of oxygen and water in the corroding system. Undoubtedly the significant decrease of the corrosion rate may be expected.

The level of the ambient temperature and its increase may be the significant factors of the corrosion of 
metals in all. In many cases a vehement exponential increase of the corrosion rate of the metal may be observed when the temperature is increased. When the corrosion process is conditioned by the oxygen depolarization, the dependence of the corrosion rate is intensified by the flow and diffusion of oxygen. But at the same time the oxygen concentration in the solution is decreased. Therefore, the temperature increase may accelerate the corrosion of the metal, in the beginning of the process, but inhibit it at its later stage (Akimov 1953; Kaesche 1979).

Regardless of the significance of the influence of temperature on the rate of corrosion of concrete reinforcement, the related data in the literature are very sporadic and limited. For example, Tuutti (1979) considers the ambient temperature with oxygen diffusion for the significant controlling factor of the corrosion process. According to him, in the interval of -20 to $+20^{\circ} \mathrm{C}$ the dependence of corrosion rate is linear, and the corrosion rate increased 100 times. However, in the interval +10 to $+20^{\circ} \mathrm{C}$ the rate of increase was only 7 times. Schiessel and Raupach $(1988,1990)$ showed that when the ambient temperature was increased from 15 to $20^{\circ} \mathrm{C}$, corrosion current increased by about $50 \%$. These data show and confirm the significance of the ambient temperature as a factor of the rate of steel reinforcement corrosion.

We present here the results of the experimental study on the influence of the increase of the ambient temperature on the rate of chloride induced corrosion of concrete reinforcement.

\section{Experimental}

Ordinary Portland cement [STN 722121 Portland cement] and silica sand [STN 721208 Testing Sands] were used

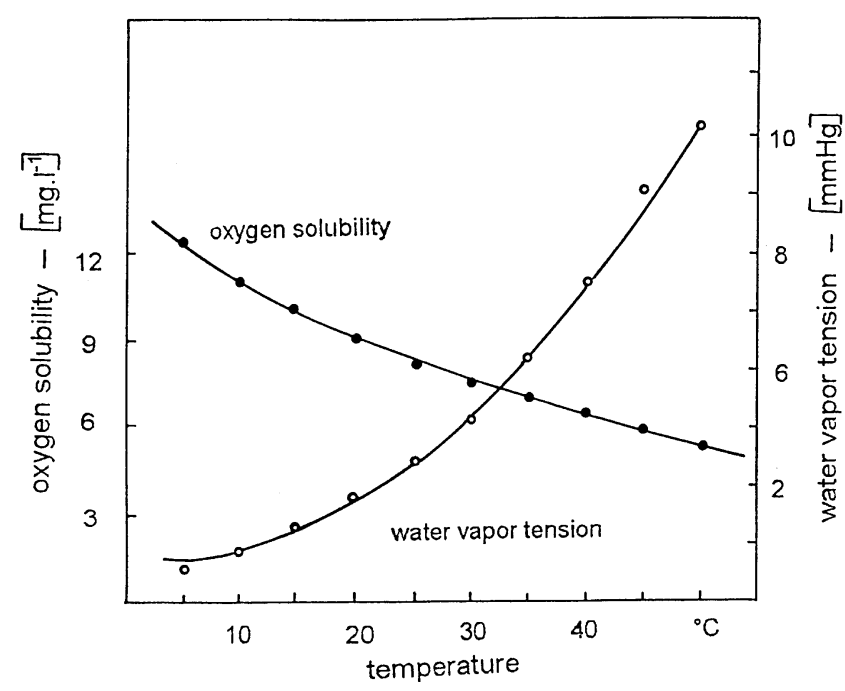

Figure 1. Dependence of the solubility of oxygen in water and water vapour tension on the ambient temperature. in the study. Mortar mixtures with cement : sand ratio of $1: 3, \mathrm{a} \mathrm{CaCl}_{2}$ portion of $4 \%$ (opposite to the cement portion) and w/c of 0.60 were prepared. From mortar mixture, the test specimens (prisms $40 \times 40 \times 160 \mathrm{~mm}$ ) with the embedded steel specimens were prepared. For their preparation, steel 11373 [STN 411373 Steel 11373] was used. The characteristics of the used steel are shown in table 1 .

The curing procedure of the test prisms was as follows: the first 3 days after the preparation at a relative humidity (RH) of $\sim 95 \%$ at $20^{\circ} \mathrm{C}$, then at same $\mathrm{RH}$ and temperature of 20,40 and $60^{\circ} \mathrm{C}$.

During the study the stationary electrode potential and electrical resistance of the embedded steel specimens were assessed. The methods used were: method of electrode potential using saturated calomel reference electrode and improved method of electrical resistance for the measurement of the electrical resistance of the embedded steel specimens and the rate of their corrosion. The embedded steel specimens represented the suitably modified steel specimens also called corrosion sensors. More detailed information about the methods used are given elsewhere (Živica 1998, 2000).

\section{Results and discussion}

The changes found in electrode potential (EP) of the embedded steel test specimens in mortar were very irregular. Therefore, it was possible to evaluate only common trends in these changes. The results given in table 2 indicate the corrosive active state of the steel test

Table 1. Chemical composition, structure and mechanical properties of steel 11373 used.

\begin{tabular}{llccc}
\hline $\begin{array}{l}\text { Chemical } \\
\text { composition } \\
(\%)\end{array}$ & Structure & $\begin{array}{c}\text { Yield } \\
\text { point } \\
(\mathrm{MPa})\end{array}$ & $\begin{array}{c}\text { Tensile } \\
\text { strength } \\
(\mathrm{MPa})\end{array}$ & $\begin{array}{c}\text { Ductility } \\
(\%)\end{array}$ \\
\hline C 0.15 & $\begin{array}{l}\text { Ferritic with } \\
\text { particles of }\end{array}$ & 226 & 363 & 26 \\
P 0.12 & $\begin{array}{l}\text { cementite } \\
\text { S } 0.03\end{array}$ & & & \\
\hline
\end{tabular}

Table 2. Stationary electrode potential values of embedded steel test specimens.

\begin{tabular}{|c|c|c|c|}
\hline \multirow{2}{*}{$\begin{array}{l}\text { Initial } \\
\text { value }^{\mathrm{a}}\end{array}$} & \multicolumn{3}{|c|}{$\begin{array}{c}\text { Values }{ }^{\mathrm{b}} \mathrm{EP} \text { in } \mathrm{mV} \text { vs SCE at the curing of } \\
\text { temperature }\left({ }^{\circ} \mathrm{C}\right)\end{array}$} \\
\hline & $20^{\circ}$ & $40^{\circ}$ & $60^{\circ}$ \\
\hline$-508 \mathrm{mV}$ & -330 & -390 & -390 \\
\hline
\end{tabular}

Mortar: w/c $0 \cdot 6,4 \% \mathrm{CaCl}_{2}$ opposite to the cement content steel 11373.

a after 3 days of hardening at $20^{\circ} \mathrm{C}, 95 \% \mathrm{RH}$; ${ }^{\mathrm{b}}$ after 60 days of curing. 
specimens at the beginning of the measurement with the $\mathrm{EP}$ values of $-508 \mathrm{mV}$ SCE indicating the electrochemically active state. But at the end of the measurement, a decrease was seen showing the EP values of $-390 \mathrm{mV}$ SCE, at the curing temperature of $40^{\circ}$ and $60^{\circ} \mathrm{C}$, and the $\mathrm{EP}$ value of $-330 \mathrm{mV} \mathrm{SCE}$ at the curing temperature of $20^{\circ} \mathrm{C}$ indicating the passivating conditions. The results showed that the embedded steel test specimens during a certain time period were in a corrosive active state and the tendency of its absolute extinction with the expiration of the curing time. It seems that the level of curing temperature had no significant influence on the final value of EP.

The estimation of the changes in electrical resistance enabled more interesting results. Figures 2 and 3 show expressive influence of the temperature level on the rate of corrosion of the embedded steel specimens. It is evident that the values of electrical resistance of the steel specimens or their corrosion rate, respectively, increased by the increase of ambient temperature from 20 to $40^{\circ} \mathrm{C}$. But further temperature increase to $60^{\circ} \mathrm{C}$ caused a significant decrease in the corrosion rate.

The relationship found is evidently a consequence of two conflicting partial effects of temperature increase: (i) acceleration of the steel corrosion as an electrochemical process and (ii) inhibition of the steel corrosion as a consequence of the decrease in the content of water and oxygen in the pore solution in the embedding mortar.

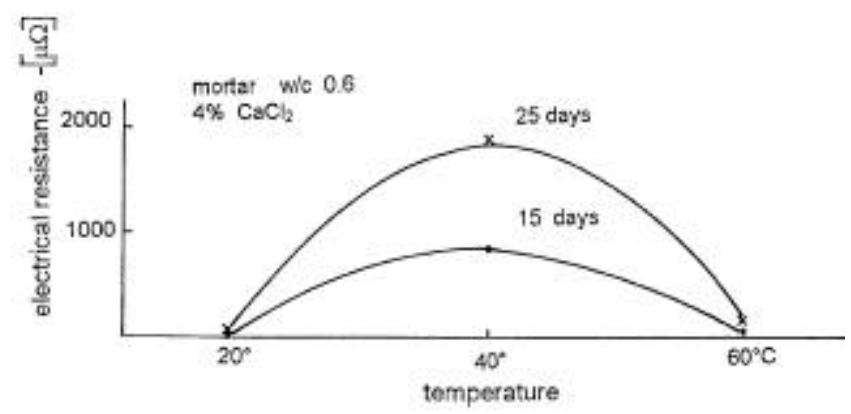

Figure 2. Dependence of chloride induced corrosion rate of steel 11373 on the ambient temperature.

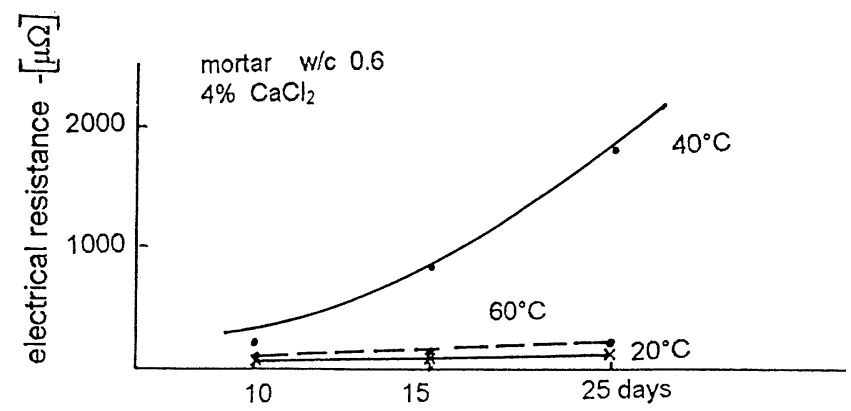

Figure 3. Dependence of corrosion of chloride induced rate of steel 11373 on the ambient temperature and time.
With the temperature increase, the significance of both partial effects changed with the prevailing significance of the effect (ii) as the ambient temperature is increased.

The character of this dependence is similar to the known temperature dependence of the corrosion of other metals conditioned by oxygen depolarization. An example is the dependence of the corrosion rate of Monell metal on the ambient temperature in aerated $\mathrm{H}_{2} \mathrm{SO}_{4}$ solution as shown in figure 4 . This similarity documents the acceleration and the following inhibition of the corrosion rate with temperature increase.

It is evident that the increase of the ambient temperature represents a factor accelerating the corrosion rate of the embedded steel to a certain limit followed by rate inhibition with further temperature increase.

Figure 4 also documents that the dependence found is not a special effect of the corrosion process of embedded steel. As may be seen in figure 4, the temperature dependence of the corrosion rate of Monnel metal in sulfate acid solution is in principle the same as of the embedded steel shown in figures 2 and 3. It confirms the similar cause of the temperature dependence of corrosion of both compared metals.

Figure 5 shows that the effect of ambient temperature increase on the rate of corrosion of a metal is dependent on whether the corroding system is open or closed (Akimov 1953; Kaesche 1979).

The case of an open system of the dependence ambient temperature - corrosion rate shown in figure 5 is identical to that found in our study. It confirms that the corroding system consisting of embedded steel - porous embedding cement material, permeable to water vapour and air or

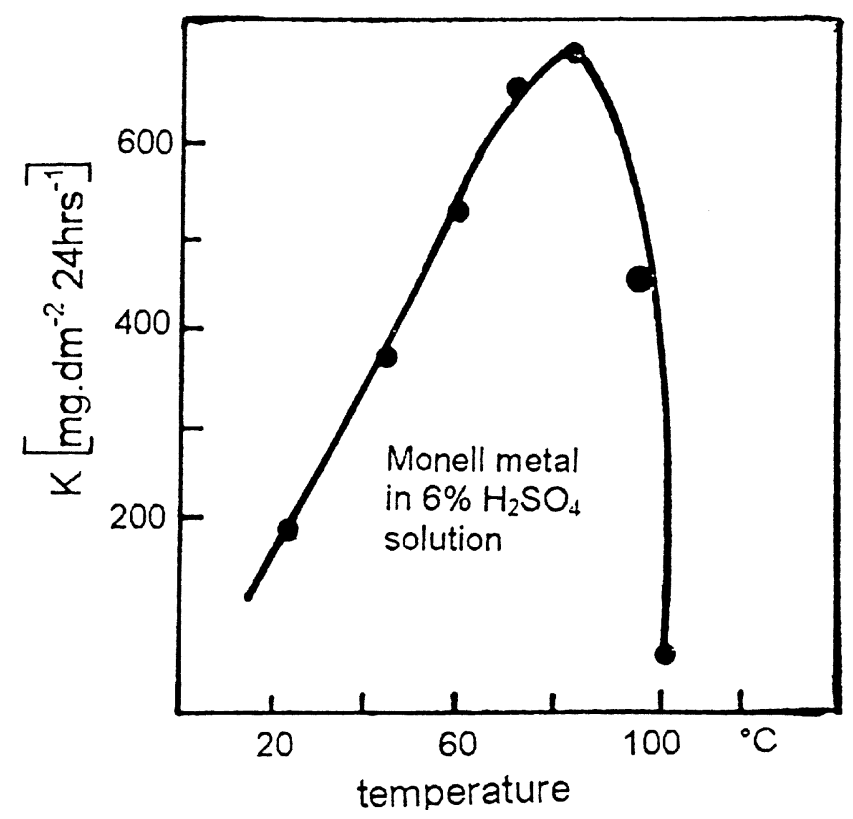

Figure 4. Dependence of the corrosion rate of Monnel metal on the ambient temperature. 


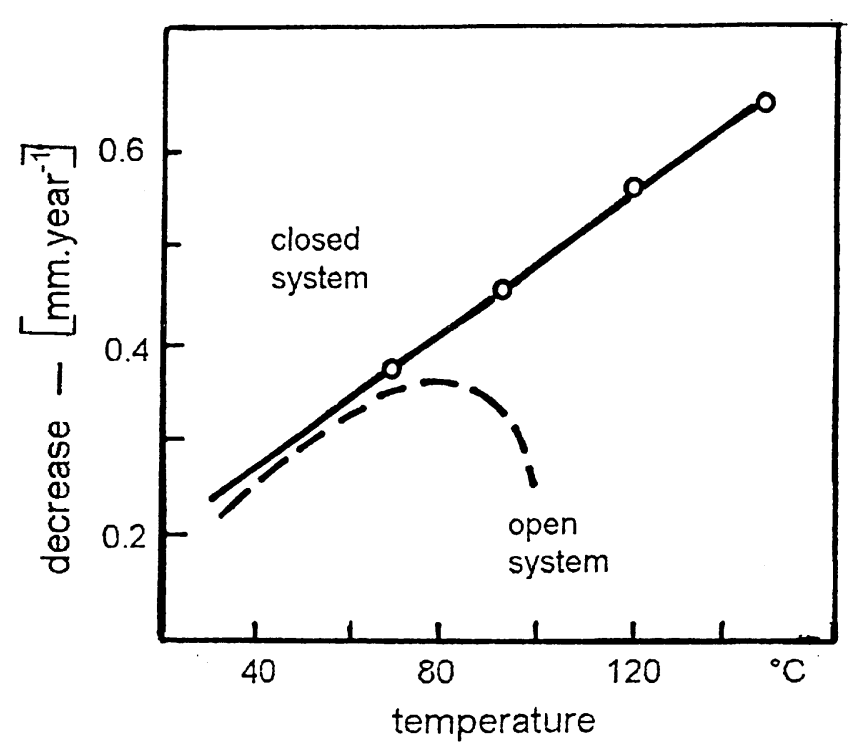

Figure 5. Temperature dependence of corrosion rate of iron on the conditions of the possibility of escape of oxygen from the corroding system.

oxygen respectively, represents an open corroding system. Therefore, the dependence of the rate of reinforcement corrosion on the ambient temperature found is not surprising.

On the basis of the results obtained the dependence ambient temperature - corrosion rate could be expressed as

$$
D R=a_{\mathrm{T}}+b_{\mathrm{T}}+c_{\mathrm{T}} T^{2},
$$

where $D R$ is the corrosion degree of the reinforcement expressed as an increase of the electrical resistance of the corrosion sensor estimated by means of the method of electrical resistance, $a_{\mathrm{T}}, b_{\mathrm{T}}$ and $c_{\mathrm{T}}$ are experimental coefficients and $T$ the ambient temperature.

As it has been shown, the corrosion rate or degree of the reinforcement may be expressed as a product of the individual function relations expressing the influence of various important factors on the corrosion rate (Živica 1998, 2000)

$$
D R=F_{1} \cdot F_{2} \cdot F_{3} \ldots F_{\mathrm{X}},
$$

where $F_{1}, F_{2} \ldots F_{\mathrm{X}}$ are the individual function relations.

Till now three function relations have been found: $F_{\mathrm{H}}$ function relation expressing the influence of the ambient humidity, $F_{\mathrm{C}}$ expressing the influence of the chloride concentration in the embedding material, and $F_{\mathrm{T}}$ expressing the influence of the time of the exposition. Equation (4) represents a new further function relation, $F_{\mathrm{T}}$, expressing the influence of the ambient temperature on the corrosion rate as a member in the product of the individual function relations expressed by (5).

This equation enables the possibility of the quantitative evaluation of the corroding reinforcement in the dependence of the ambient humidity and temperature and chlo-
Table 3. Values of the experimental coefficients.

\begin{tabular}{ccccc}
\hline & \multicolumn{4}{c}{ Experimental coefficients } \\
\cline { 2 - 5 } Equation (4) & $\begin{array}{c}\text { Time of the } \\
\text { exposition days }\end{array}$ & \multicolumn{1}{c}{$a_{\mathrm{T}}$} & $b_{\mathrm{T}}$ & $c_{\mathrm{T}}$ \\
\hline & 10 & $-531 \cdot 7$ & $36 \cdot 4$ & -0.44 \\
15 & -2375 & $160 \cdot 3$ & -1.99 \\
25 & -5378 & $362 \cdot 7$ & -4.50 \\
\hline
\end{tabular}

Table 4. Experimental and calculated values of DR.

\begin{tabular}{lccc}
\hline & & \multicolumn{2}{c}{ DR values $(\mu \Omega)$} \\
\cline { 3 - 4 } Time of & Ambient temperature & & $\begin{array}{c}\text { Calculated } \\
\text { exposition }\end{array}$ \\
\cline { 3 - 4 }$\left({ }^{\circ} \mathrm{C}\right)$ & Measured & (equation $(4))$ \\
\hline \multirow{3}{*}{10 days } & 20 & $18 \cdot 1$ & 18 \\
& 40 & 212 & $211 \cdot 7$ \\
& 60 & 50 & $49 \cdot 5$ \\
15 days & 20 & $34 \cdot 9$ & $34 \cdot 9$ \\
& 40 & 853 & $853 \cdot 1$ \\
& 60 & 79 & $79 \cdot 3$ \\
25 days & 20 & $76 \cdot 4$ & $76 \cdot 3$ \\
& 40 & 1930 & $1929 \cdot 6$ \\
& 60 & 183 & $182 \cdot 1$ \\
\hline
\end{tabular}

ride concentration in the material and time. Naturally, the reliability of the calculated values is strongly dependent on the given conditions of the corrosion. With the increase of the difference between used experimental conditions and the given practical conditions the reliability of this mathematical approach is significantly decreased.

Calculated values of the experimental coefficients for (4) are given in table 3 .

Table 4 enables the comparison of the values of DR measured and calculated by means of (4) and (5).

\section{Conclusions}

According to the results obtained increase of ambient temperature on the rate of chloride induced corrosion has two effects: (i) acceleration of the rate when the ambient temperature is increased to about $40^{\circ} \mathrm{C}$, and (ii) inhibition of the rate when the ambient temperature is increased over the given value of the temperature.

A thorough analysis of the corrosion process shows that the decrease of the content of oxygen and water in the pore solution in the corroding system (concretesteel) as a cause of the mentioned effects.

The direct consequence of the decrease of the content in both vital reactants is the gradual inhibition of the cathodic reaction, and finally the inhibition of the corrosion process as a whole.

The similar effects of corrosion temperature increase may be expected even in the case of the corrosion of rein- 
forcement evoked by carbonation or at the action of other aggressive media disturbing the electrochemically passive condition in the reinforced material.

\section{Acknowledgement}

The author wishes to thank the Slovak Grant Agency VEGA (grant 2/7003/22) for its support.

\section{References}

Akimov G V 1953 Theory and testing methods of corrosion of metals (Praha: SNTL) (in Czech)
Kaesche H 1979 Corrosion of metals (Berlin: Springer Verlag) 2nd ed. (in German)

Schiessel P and Raupach M 1988 Beton-Informationen 2833 (in German)

Schiessel P and Raupach M 1990 Beton-Informationen 3043 (in German)

STN 722121 Portland Cement

STN 721208 Testing Sands

STN 411373 Steel 11373

Tuutti K 1979 Service life of structures with regard to corrosion of embedded steel (Stockholm, Sweden: RILEM Quality Control of Concrete Structures) p. 293

Živica V 1998 Construct. \& Build. Mater. 12365

Živica V 2000 Construct. \& Build. Mater. 14351 